\title{
Explaining Variability in Caries Experience Using an Ecological Model
}

\author{
JOANNA JENNY, P. JEAN FRAZIER, ROBERT A. BAGRAMIAN, \\ and JOHN M. PROSHEK \\ Division of Health Ecology, School of Dentistry, University of Minnesota, Minneapolis, \\ Minnesota 55455, USA and Department of Community Dentistry, School of \\ Dentistry, University of Michigan, Ann Arbor, Michigan
}

A model including diet, oral hygiene, and dental treatment and three ecological levels was tested to study variability in caries experience. Analysis produced a rank order of explanation for the ecological variables: (1) cominunity, (2) family, (3) individual. The treatment factor contributed more to oral condition than oral hygiene or diet within each ecological level.

In this paper we present the findings of a study designed to test the usefulness of an ecological model containing factors believed to affect children's oral health both directly and indirectly. It has long been accepted that there are multiple factors involved in the etiology of dental disease-in this case, caries. However, most dental research uses explanatory models involving a limited range of variables.

Investigators who study relationships between caries and factors in the oral cavity often use only one independent variable. Gustafsson et al ${ }^{1}$ studied the relationship between diet (sucrose) and caries experience. Barenie, Leske, and Ripa ${ }^{2}$ related oral hy. giene to caries experience in children. Littleton, Kakehashi, and Fitzgerald ${ }^{3}$ isolated caries-inducing microorganisms from carious lesions.

Duany, Jablon, and Zinnert studied the effects of two independent variables by relating diet and oral hygiene to the oral condition of caries-free and caries-active students.

Littleton, Kakehashi, and Fitzgerald ${ }^{5}$ used a three-factor model to study the relationship

Supported by USPHS Grant DH 00183-01.

Presented at the $51 \mathrm{st}$ general session of the IADR in Washington, DC, April 1973.

Received for publication June 28, 1973. between race, microorganisms, and diet to caries prevalence.

Kegeles, ${ }^{6}$ Rayner, ${ }^{7}$ and $\mathrm{O}^{\prime}$ Shea and Gray ${ }^{8}$ have studied the relationships of factors in the individual's social environment. In these studies the dependent variables are dental attitudes or behaviors such as diet practices, oral hygiene practices, and the frequency and purpose of dental visits. In most studies of dentistry that use social science methods, the relationships between the dependent variables and oral condition are assumed.

The multiplicity of factors involved in the caries process suggested to the investigators that it might be fruitful, in a study of caries experience in a natural population, to examine concurrently as many as possible of the factors believed to be associated with the processes and conditions affecting the disease.

An ecological approach was used to conceptualize factors affecting children's caries experience. The theoretical model that evolved is based on theories of the pathogenesis of dental disease, and the findings of clinical, experimental, epidemiological, and behavioral science research in dentistry. The model reflects the idea that the occurrence and progress of dental disease are the result of many interrelated factors. those relating specifically to the oral environment and those relating to the individual's social environment-his family and his community.

The comprehensive ecological model that determined the study design is fully described in another paper. ${ }^{9}$ The model does not present new theories regarding the cause of caries, nor does it introduce new facts about control or prevention of caries. Rather, the model was intended to illustrate the pervasiveness of factors in a child's total envi- 
ronment which influence his oral health. It provides a comprehensive ecological framework for studying the caries process within a natural population.

With the use of this comprehensive model as a guide, the overall research objective was to examine the prevalence and incidence of caries as a function of processes or conditions existing within the oral cavity which are or were affected by the individual child, his family, and his community. Diet, oral hygiene, and dental treatment were the only intraoral factors in the model selected for study. Although oral microorganisms and genotypic factors were included in the model as intraoral factors, the contributions of these two factors to explaining variability in incidence or prevalence of caries were not studied in this investigation.

\section{Materials and Methods}

SAMPLE SELECTION.-The study sample consisted of 838 white third-grade children and their parents. The children attended 14 public schools from a total of 69 schools selected to represent a broad spectrum of socioeconomic levels in a large midwestern city school district. The public water supplies of this city have been fluoridated since 1957 . Seventy percent of the study children had experienced fluoride exposure for their total life.

DATA COLLECTION.-Information was obtained from both children and parents over a one-year period. Each child was individually interviewed twice-once in the third grade and again in the fourth grade-by a trained community resident interviewer. Primarily, data concerning the child's diet and oral hygiene practices were obtained during these interview sessions. A few questions related to family attitudes and to past dental experiences were also asked.

Children rather than parents were interviewed because Babchuck and Gordon ${ }^{10}$ reported that they found children to be spontaneous communicators of the fact rather than of the calculated response. They found that threatening questions met with resistance from adults but not from children. Therefore, it was believed that children would provide more spontaneous and reliable information about dentally related practices and attitudes than would their parents.

After each of the two diet interviews each child received an unannounced dental screening examination by a dentist trained in dental epidemiology. Oral condition, in terms of caries and oral hygiene indexes, was assessed. Children were identified as needing dental treatment if an obvious carious lesion was observed on one or more permanent teeth.

Data concerning family characteristics were collected from the child's parents (most often the mother) during the year between the first and second children's interviews and dental examinations. Demographic informa. tion, attitudes, and behaviors regarding dental practices were collected from the families of $93 \%$ of the children. Parents whose children were identified as needing dental treatment for an obvious carious lesion on a permanent tooth, plus a randomly selected group of 100 parents whose children did not meet that criterion, were interviewed at home by a trained community resident. The remaining parents received a mail questionnaire to obtain exactly the same information as that collected during the home interviews.

The specific interview, questionnaire, and dental examination data that comprise the independent variables are shown in Table 1. The four dependent variables were: DMFSprevalence, DMFS-incidence, defs-prevalence, and defs-incidence.

ANalysis.-The procedure followed in the analysis of these data was multiple regression in which the dependent variables were each regressed on the independent variables, that is, the items composing the factors in the general model and subsets of these factors. Table 1 gives the questionnaire, interview, and dental examination items that make up the elements of each of the ecological levels. or factors, in the general modelindividual, family, and community. The individual factor included variables such as oral hygiene practices, frequency and amounts of cariogenic food ingested, and acceptance of dental treatment and recommendations for home care. The family factor included variables such as provision of cariogenic foods, supervision of oral hygiene procedures, and provision of preventive and corrective dental care. The community factor included variables such as fluoride exposure, availability, accessibility, and acceptability of dental treatment services.

Regression analyses were performed in which all possible combinations of these three factors were considered as the regressor variables. From the results of these regressions it was possible to determine for each 


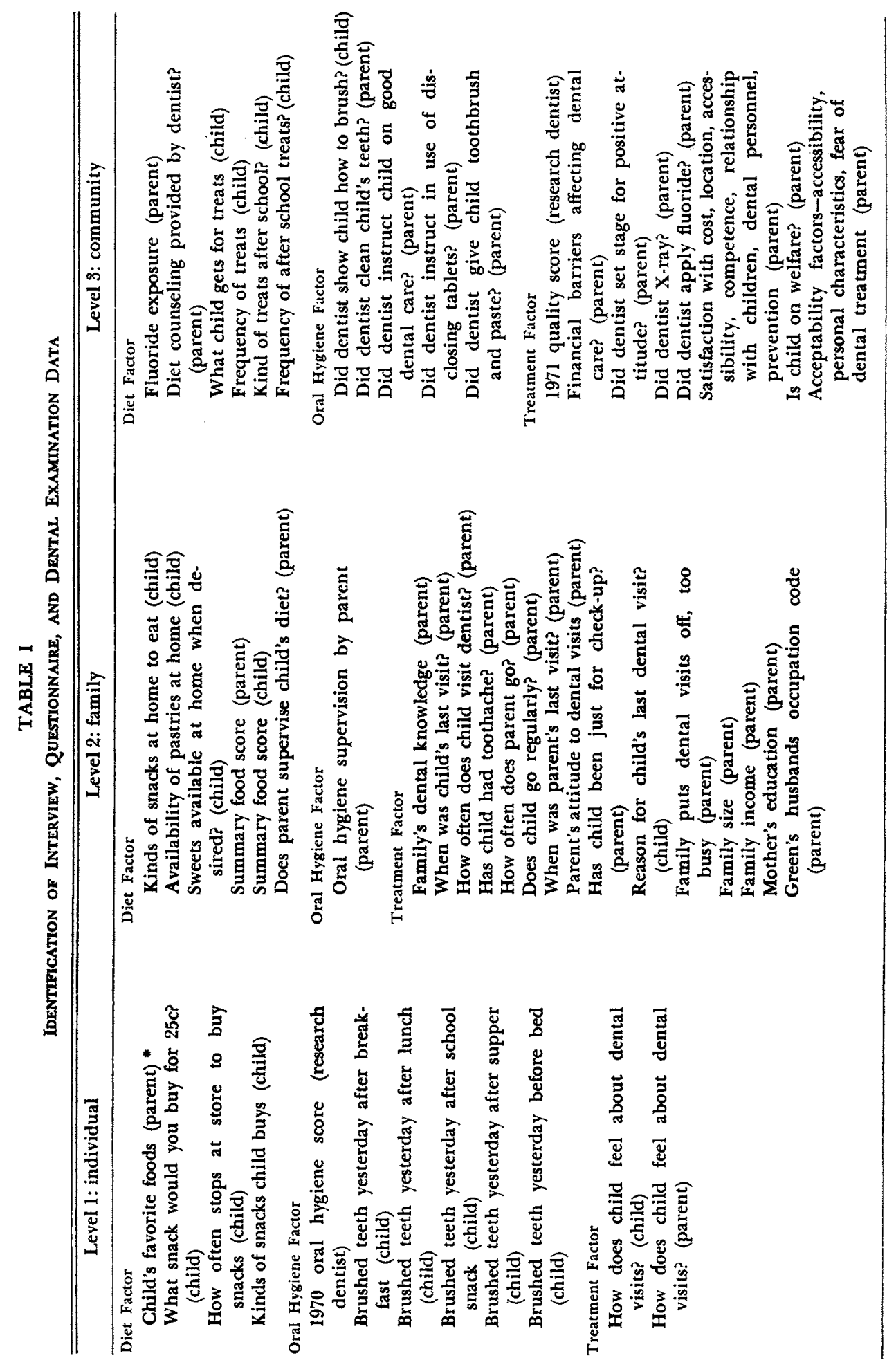


factor in the model: its unique contribution to the variance explained in the full model, the second-order contribution to the variance that was due to each pair-wise combination of factors, and the third-order contribution to the variance in the full model, which could only be explained by the combination of all three factors jointly.

To further explain this procedure, the illustration provides a visual representation of the concepts of unique, second-order, and third-order contributions of the factors in the model to the explanation of the variance of the dependent variable. These contributions also have been termed "commonalities" in the literature. ${ }^{11}$ In representational terms, the area of the box labeled $W$ could be considered the total variance of the dependent variable in a regression problem. When this variable is regressed upon a set of variables, the resultant $R^{2}$ is a measure of the proportion of the variance of the dependent variable which is in common with the inde- pendent variables in the regression modelthe proportion of the variance "explained" by the model. This value is represented by the total area enclosed by the three overlapping circles in the illustration. Each circle is representative of the proportion of variance explained by that individual factor when the dependent variable is regressed upon just that factor. The portion of each circle that does not overlap one of the other circles is representative of the proportion of the variance which is uniquely explained by that variable in the regression model. The overlapping areas of the circles then can be defined as higher order commonalities or contributions of the independent variables in explaining the variance of the dependent variable in the regression model. These areas defined as the secondorder commonalities are then representative of the proportion of the variance of the dependent variable that can only be explained jointly by two of the factors in the model.

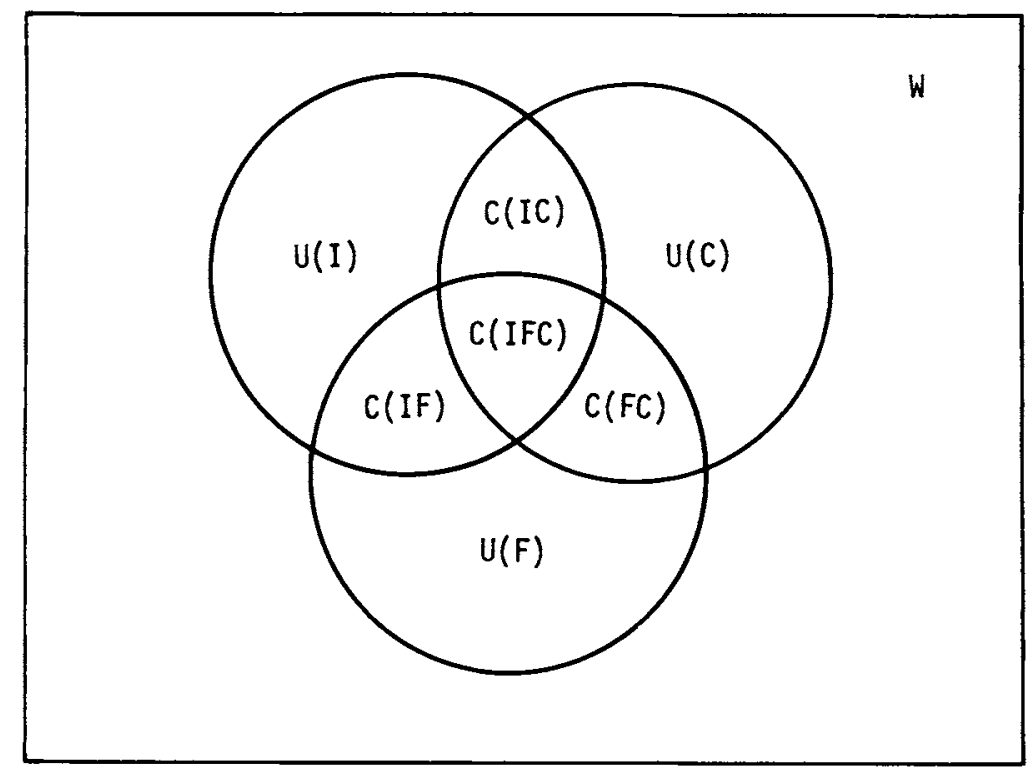

Analysis of variance. $W$, total variance of dependent variable $(Y)$ in model, $1.000 ; U(I)$, proportion of variance of $Y$ uniquely accountable by individual in model; $U(F)$, proportion of variance of $Y$ uniquely accountable by family factor in model; $U(C)$, proportion of variance of $Y$ uniquely accountable by community factor in model; $C(I F)$, proportion of variance of $Y$ jointly accountable by individual and family factors (second-order commonality); $C(I C)$, proportion of variance of $Y$ jointly accountable by individual and community factors (second-order commonality); $C(F C)$, proportion of variance of $Y$ jointly accountable by family and community factors (second-order commonality); $C(I F C)$, proportion of variance of $Y$ jointly accountable by individual, family, and community factors (third-order commonality). 
In the case of three variables in the model, there are three second-order commonalities. Higher order commonalities exist, the limiting order of which is determined by the number of variables in the model; for example, in a three-factor model the highest order commonality is of the third-order-that proportion of the variance of the dependent variable which can be explained only by the joint relationship of the three factors. The sum of the commonalities equals $R^{2}$ obtained from the regression analysis, which includes the appropriate factors of the model.

\section{Results}

Table 2 gives the results of the regression analysis and the resultant commonalities for the dependent variable, DMFS-prevalence. Table 3 gives the results of the regression analysis and resultant commonalities for the dependent variable, DMFS-incidence. Tables 4 and 5 give the results of the regression analyses and the resultant commonalities for the deperident variables, defs-prevalence and defs-incidence, respectively.

The top portion of each table gives the analysis of the full model using the three ecological factors of individual, family, and community as the factors or independent variables in the regression model. For example, as shown in part $A$ of Table 2, the general model explained $21 \%$ of the variance observed in the DMFS-prevalence scores. The commonality contributions of the factors are given: the unique contribution of the individual factor was $2 \%$, the unique contribution of the family factor was $7 \%$, and the unique contribution of the community factor was $12 \%$.

In this instance, each of the higher order commonalities contributed less than $1 \%$ toward the explanation of the variance in DMFS-prevalence. The second-order commonalities were negative in value, which could be indicative of a "masking" effect of the joint contributions. This masking effect could be interpreted through the analogy of interaction of differential effects. The fact that such negative results are possible is thoroughly explained by Newton and Spurrell.12 A more theoretical approach and explanation of this analytic procedure was presented by Rozeboom.13 A practical application of this methodology in an expanded form was done by Mayeske et al. ${ }^{11}$
In addition, within the individual factor, within the family factor, and within the community factor, diet, oral hygiene, and treatment were analyzed using the same methodology. The results of these analyses are presented in the second half of Tables 2-5 as second level models for each of the four dependent variables. For example, when DMFS-prevalence was regressed upon the ecological factor of community, it was found that this factor accounted for, or explained, $11.89 \%$ of the variance of DMFSprevalence. Within this contribution, the contributions of diet, oral hygiene, and treatment were determined and are given in part $B$ of Table 2 under the second level models section of community contribution. It can be observed that the treatment factor explained approximately $7 \%$ of the variance, oral hygiene explained approximately $2 \%$, and the treatment and oral hygiene factors jointly explained about $1 \%$ of the variance, whereas the diet factor explained less than $1 \%$.

\section{Discussion}

The ecological model which contains factors believed to affect children's oral health provided an organized approach to the assessment of the contributions of various factors in explaining caries experience. Use of the model both in data collection and in conducting the analysis allowed consideration of a broad range of variables and combinations of variables believed to be contributory to oral health-those relating to the individual's oral environment and those re. lating to his social environment (his family and his community).

This study centered on the influence of three of the five primary factors believed to be associated with the caries process, oral hygiene, diet, and dental treatment, within the framework of three ecological factorsthe individual, his family, and his community. This study did not include an assessment of the contribution of the factor of caries-inducing microorganisms or the factor of genotype of the individual.

Oral hygiene, diet, and dental treatmentexamined within the contexts of individual, family and community-together explained approximately $20 \%$ of the variability in the caries experience of the study population. The remaining proportion of the variability in caries experience may be accounted for 

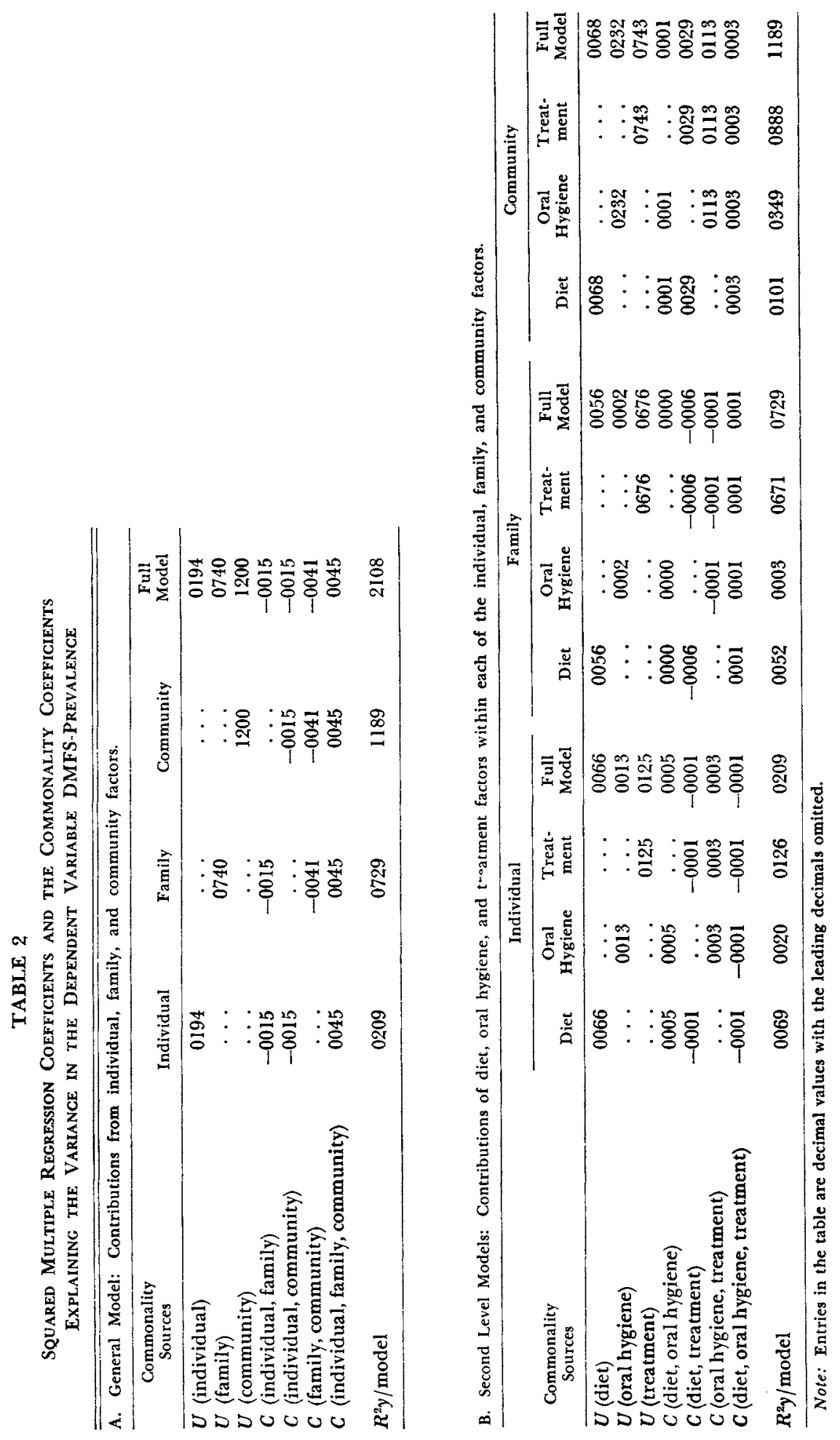

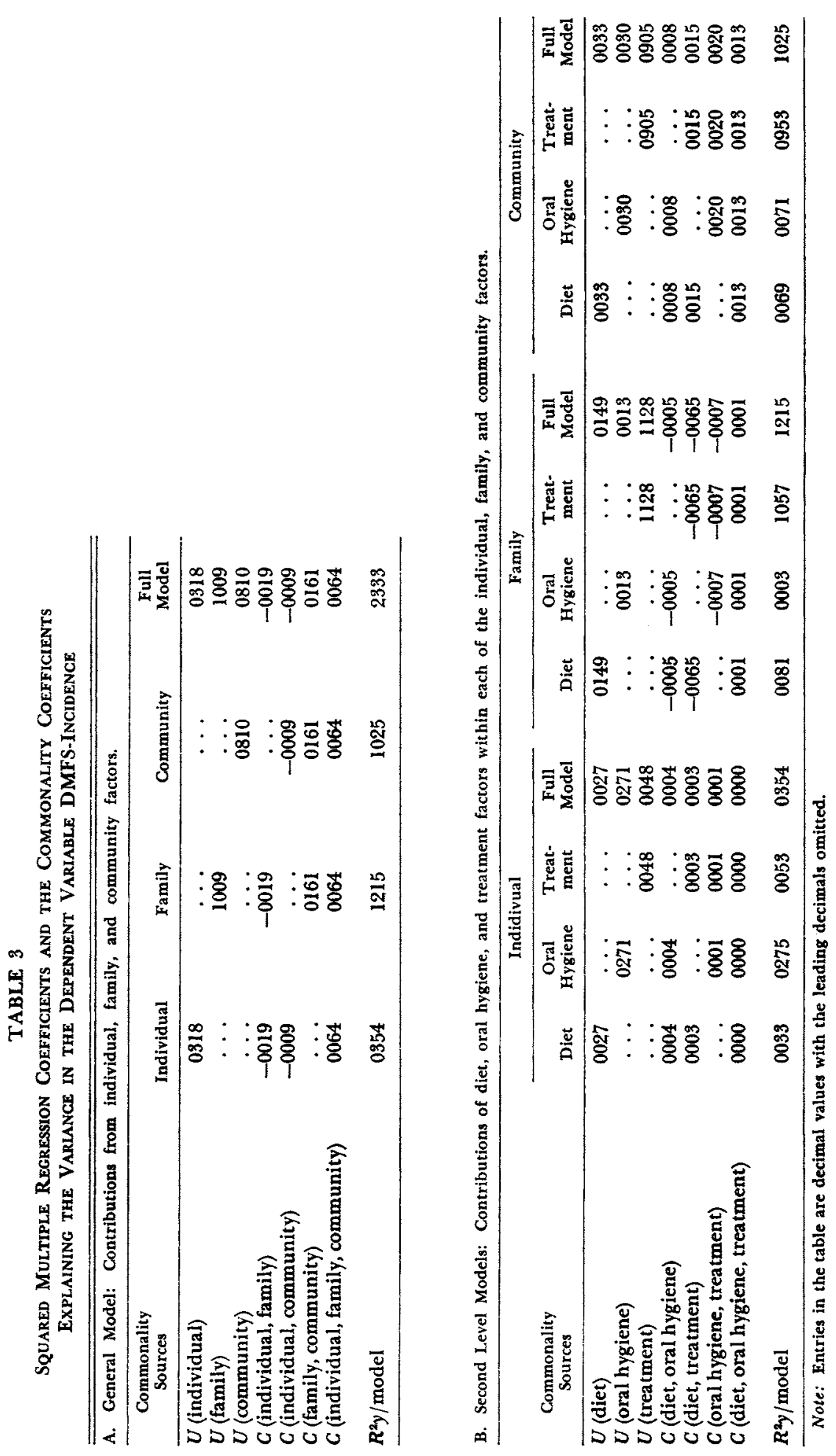

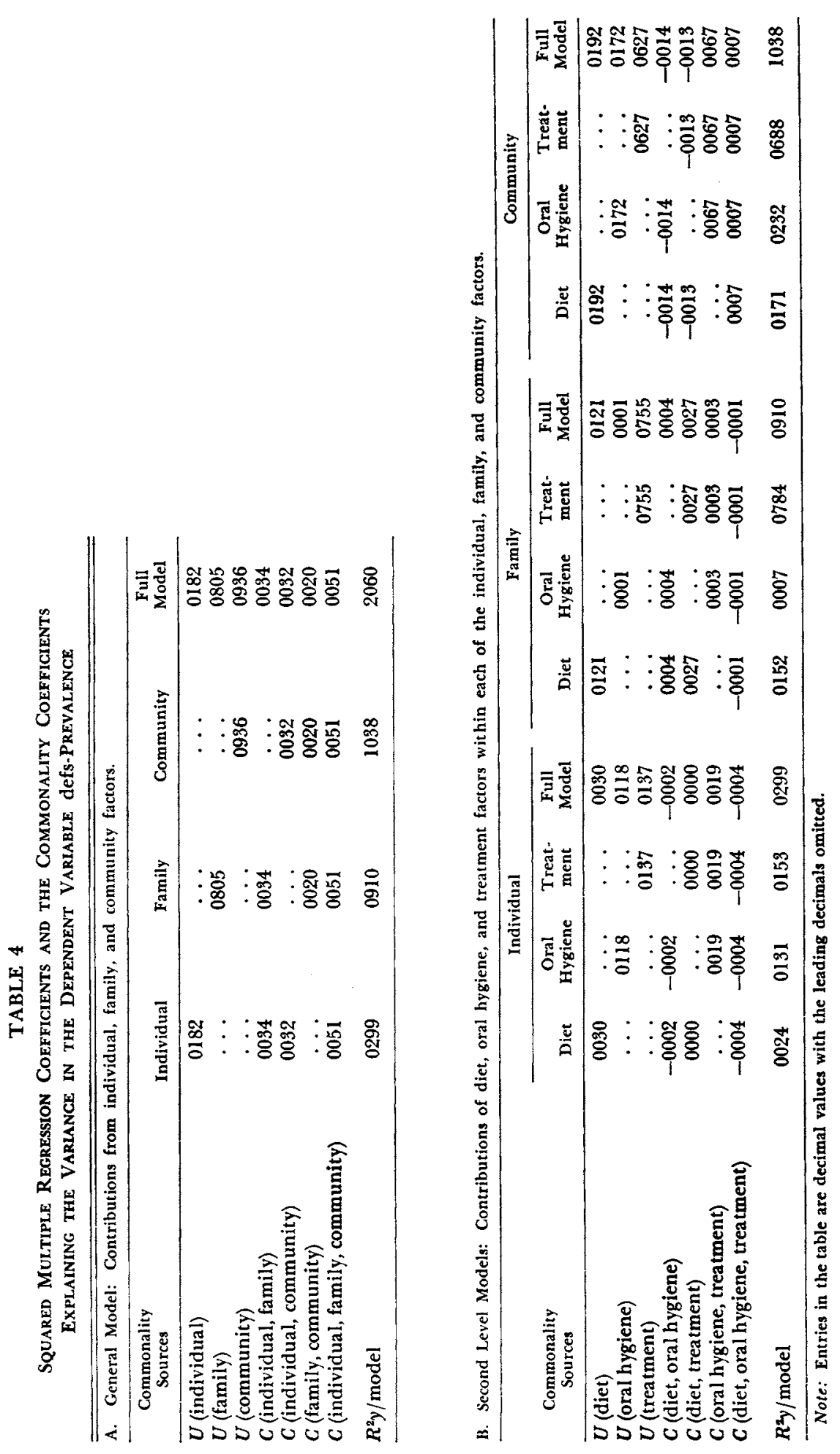

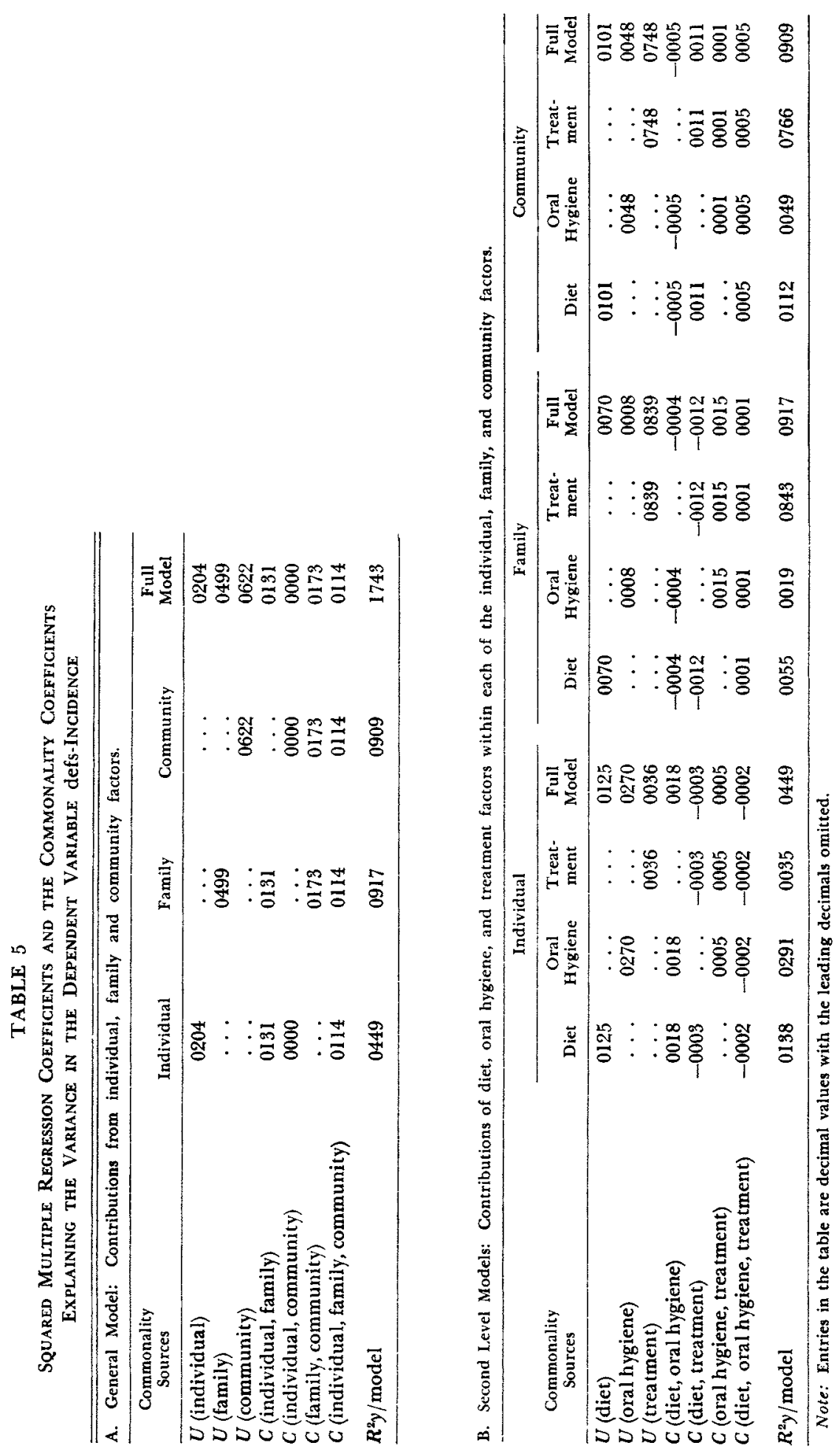
TABLE 6

Summary Rankings of Commonality Coffficients

\begin{tabular}{|c|c|c|c|c|c|c|c|c|}
\hline & \multicolumn{2}{|c|}{$\%$ DMFS-Prevalence } & \multicolumn{2}{|c|}{$\%$ DMFS-Incidence } & \multicolumn{2}{|c|}{$\%$ defs-Prevalence } & \multicolumn{2}{|c|}{$\%$ defs-Incidence } \\
\hline Ecological model & $\begin{array}{l}U(C)^{*} \\
U(F) \\
U(I)\end{array}$ & $\begin{array}{r}12 \\
7 \\
2\end{array}$ & $\begin{array}{l}U(F) \\
U(C) \\
U(I) \\
C(F, C)\end{array}$ & $\begin{array}{r}10 \\
8 \\
3 \\
2\end{array}$ & $\begin{array}{l}U(C) \\
U(F) \\
U(I) \\
C(I, F, C,)\end{array}$ & $\begin{array}{r}9 \\
8 \\
2 \\
1 / 2\end{array}$ & $\begin{array}{l}U(C) \\
U(F) \\
U(I) \\
C(F, C) \\
C(I, F) \\
C(I, F, C)\end{array}$ & $\begin{array}{l}6 \\
5 \\
2 \\
2 \\
1 \\
1\end{array}$ \\
\hline $\begin{array}{l}\text { Second-level models } \\
\text { Within community }\end{array}$ & $\begin{array}{l}U(T r t) \dagger \\
U(O H) \\
C(O H, T) \\
U(D)\end{array}$ & $\begin{array}{r}7 \\
2 \\
1 \\
2 / 3\end{array}$ & $U(T r t)$ & 9 & $\begin{array}{l}U(T r t) \\
U(D) \\
U(O H) \\
C(O H, T)\end{array}$ & $\begin{array}{r}6 \\
2 \\
2 \\
2 / 3\end{array}$ & $\begin{array}{l}U(T r t) \\
U(D) \\
U(O H)\end{array}$ & $\begin{array}{r}7 \\
1 \\
1 / 2\end{array}$ \\
\hline Within family & $\begin{array}{l}U(T r t) \\
U(D)\end{array}$ & $\begin{array}{r}7 \\
1 / 2\end{array}$ & $\begin{array}{l}U(T r t) \\
U(D) \\
C(D, T)\end{array}$ & $\begin{array}{r}11 \\
1 \\
1 / 2\end{array}$ & $\begin{array}{l}U(T r t) \\
U(D)\end{array}$ & $\begin{array}{l}8 \\
1\end{array}$ & $\begin{array}{l}U(T r t) \\
U(D)\end{array}$ & $\begin{array}{r}8 \\
2 / 3\end{array}$ \\
\hline Within individual & $\begin{array}{l}U(T r t) \\
U(D)\end{array}$ & $\begin{array}{r}1 \\
2 / 3\end{array}$ & $\begin{array}{l}U(O H) \\
U(T r t)\end{array}$ & $\begin{array}{r}3 \\
1 / 2\end{array}$ & $\begin{array}{l}U(\operatorname{Tr} t) \\
U(O H)\end{array}$ & $\begin{array}{l}1 \\
1\end{array}$ & $\begin{array}{l}U(O H) \\
U(D)\end{array}$ & $\begin{array}{l}3 \\
1\end{array}$ \\
\hline
\end{tabular}

Note: The figures given above have been rounded and converted to percentages from Tables $2-5$. Coefficients of less than $1 / 2 \%$ contribution to the explanation of the variance have been deleted.

* $C$, community; $F$, family; $I$, individual.

+ Trt, treatment; $O H$, oral hygiene; $D$, diet.

by other factors. Potentials for explaining the remaining proportion of the variability probably reside in the following three areas: elements associated with caries which were not identified in the theoretical model; the contributions of two factors in the theoretical model, microorganisms and genotype, which were not assessed in this study; and errors in measurement and sampling associated with the collection of data.

Another possible source of error might have involved differential populations or curvilinear relationships. Since the analysis of the data showed that the model explained only $20 \%$ of the variability in oral condition, it was thought that there might have been some confounding of results because of differential populations or curvilinear relationships among some of the elements of the model and the dependent variable-oral condition. To determine whether these in fluences may have had an effect, the data were subjected to additional analyses by which the high-incidence children were compared with a comparable number of no-in cidence children on each of the items comprising the model. The results of these many analyses did not contradict the findings from the regression analysis. The originally anticipated contributions of diet and oral hygiene were not significant for extreme cases of caries experience. Therefore, it may be assumed that the unexplained variance is not due to the effects of differential populations or curvilinear relationships.

Within the context of the three ecological factors studied-individual, family, and community-Table 6 summarizes the most important findings presented in Tables 2-5. In three of the four dependent variables, DMFS-prevalence, defs-prevalence, and defsincidence, the community factor explained the greatest amount of variability. In this study the contributions of the individual's dental behaviors, attitudes, and conditions have been demonstrated to be less explanatory of dental caries than those of either his community or his family.

Dental treatment, including such items as length of time since last visit, reason for last visit, and parents' satisfaction with the dentist, is shown in Table 6 to be the most contributory factor in explaining variability in caries experience within both the community and family factors.

The oral hygiene factor, including oral hygiene score and supervision of oral hygiene practices by parents, and the diet factor, including frequency and kinds of treats consumed by the child, each contributed less than the treatment factor to the explanation of variability in caries experience in the study population.

The importance of the treatment factor 
in caries experience was further illustrated by the highly significant relationship of caries incidence in permanent teeth and the ratio of decayed to filled teeth $(D / F)$ determined during the base line examination. Children with a high $D / F$ ratio were found, 12 months later, to have experienced a greater incidence of caries in permanent teeth.a

\section{Conclusions}

Some preventive programs place emphasis on efforts to make the individual independent of the dentist ${ }^{14}$ by encouraging him to practice personal oral hygiene procedures and diet control. The results of this study indicate, however, that community and family factors are more powerful and more pervasive in their influence on the individual child's oral health than is generally acknowledged and that dental treatment is a vital element for achieving oral health. Therefore, efforts to improve children's oral health primarily through educational programs designed to promote positive personal oral hygiene and diet practices in the individual may be less than adequate if concurrent treatment services are not provided.

\footnotetext{
a D/F ratio and increment of caries on permanent teeth were cross-tabulated using top incidence scores $(N=179)$ and an equivalent number $(N=166)$ of zero incidence scores, randomly selected $\left(X^{2}(3 d f)=\right.$ $35.047, P<0.001$ )
}

\section{References}

1. Gustafsson, B.E.; Quensel, C.E.; Lanke, L.S.; Lundquist, C.; Grahnen, H.; Bonow, B.E.; and Krasse, B.: The Vipeholm Dental Caries Study. The Effects of Different Lev. els of Carbohydrate Intake on Caries Activity in 436 Individuals Observed for Five Years, Acta Odontol Scand 11: 232-264, 1954.

2. Barenie, J.; Leske, G.; and RipA, L.: Relationship Between Toothbrushing Frequency and the Oral Health of School Children, J Dent Res 52 (Special Issue): Abstract No. 244, 1973.
3. Littleton, N.W.; Kakehashi, S.; and FitzGERALD, R.J.: Recovery of Specific "Cariesinducing" Streptococci from Carious Lesions in the Teeth of Children, Arch Oral Biol 15: 461-463, 1970.

4. Duany, L.F.; Jablon, J.M.; and Zinner, D.D.: Epidemiologic Studies of Caries-free and Caries-active Students, $J$ Dent Res 51: 727-733, 1972.

5. Littleton, N.W.; Kakehashi, S.; and FitzGERALD, R.J.: Study of Differences in the Occurrence of Dental Caries in Caucasian and Negro Children, J Dent Res 49: 742-751, 1970.

6. Kegrles, S.S.: Some Motives for Seeking Preventive Dental Care, JADA 67: 90-98, 1963.

7. RAYNER, J.F.: Socioeconomic Status and Factors Influencing the Dental Health Practices of Mothers, Am J Public Health 60: 1250-1258, 1970.

8. O'Shea, R.M., and Gray, S.B.: Dental Patients' Attitudes and Behavior Concerning Prevention, Public Health Rep 83: 405-410, 1968.

9. Jenny, J.: Preventing Dental Disease in Children: An Ecological Approach, $\mathrm{Am} J$ Public Health, in press, 1973.

10. Babchuk, N., and Gordon, C.W.: The Child as a Prototype of the Naive Informant in the Interview Situation, Am Sociol Rev 23: 196-198, 1958.

11. Meyeske, G.W.; Wisler, C.E.; Beaton, A.E., JR.; Weinfeld, F.D.; Cohen, W.M.; OKadA, T.; Proshek, J.M.; and Tabler, K.A.: $A$ Study of Our Nation's Schools, DHEW Pub. lication No. (OE) 72-142, Washington, DC: US Government Printing Office, 1972, p 360.

12. Newton, R.G., and Spurrell, D.J.: A Development of Multiple Regression for the Analysis of Routine Data, Appl Stat 16:51-64, 1967.

13. Rozenoom, W.W.: The Theory of Abstract Partials: An Introduction, Psychometrika, 33: 133-168, 1968.

14. Community Dental Health Education of the Poor: Problems, Perspectives, and Programs, Chicago: American Dental Association, 1971, p 34 . 